\title{
SEX AND THE CITY: O PROTAGONISMO FEMININO NA PÓS-MODERNIDADE
}

SEX AND THE CITY: THE LEADER FEMININE

IN POSTMDERNITY

\begin{abstract}
ROBERTO RAMOS
Doutor em Educação, professor da FAMECOS-PUCRS, Graduação e PósGraduação. Obras publicadas: Futebol: Ideologia do Poder. Grã-finos na Globo, Manipulação e Controle da Opinião Pública. A Máquina Capitalista, Mídia, Textos e Contextos (org.) e A Ideologia da Escolinha do Professor Raimundo.

E-mail: rr@pucrs.br
\end{abstract}

\begin{abstract}
RESUMO
O filme, Sex and City, contempla uma realidade em seus discursos. Evidencia o protagonismo feminino na contemporaneidade. Perfila, com o tempero de uma comédia romântica, as fortalezas e as fragilidades da mulher pós-moderna. Procuraremos, no presente ensaio, compreender e explicar os discursos do filme. Usaremos, para tanto, o Paradigma da Complexidade, de Edgar Morin, como método, contemplando as possibilidades da Transdisciplinaridade. A Semiologia, de Roland Barthes, será a técnica. Assim sendo, iremos priorizar a produção de sentido, em seus diálogos com os respectivos contextos. Palavras-chave: Ideologia. Feminino. Pós-Modernidade. Semiologia. Complexidade
\end{abstract}

\section{ABSTRACT}

The film, Sex and the City, has a reality in their speeches. Shows the female role in contemporary society. Profile, with the seasoning of a romantic comedy, the strengths and weaknesses of post-modern woman. Seek, in this test, understand and explain the words of the film. Use to both the Paradigm of Complexity, from Edgar Morin, as a method, contemplating the possibilities of Transdisciplinarity. The semiology of Roland Barthes, is the technique. Therefore, we will prioritize the production of meaning in their dialogues with their contexts.

Keywords: Ideology. Female. Post-Modernity. Semiology. Complexity. 
O filme Sex and the City parece carregar as virtudes e os defeitos de uma comédia romântica norte-americana. Evidencia conflitos básicos da contemporaneidade e os soluciona, com uma agilidade, própria da linearidade, mesclada com a superficialidade. Pode divinizar, solenemente, o reino do Pensamento Mágico, com plena densidade.

\section{Amor \& dior}

O filme possui uma origem. É a série de televisão, da HBO, que ficou no ar até 2004. O seu êxito de audiência ensejou o novo projeto, que foi lançado, em 2008, no Brasil. Mantém o foco no universo feminino, abordando as relações de quatro amigas, convivendo como um grupo. É dirigido e roteirizado por Michael Patrick King. Baseia-se nas personagens do livro, Sex and the City, de Candace Bushnell.

As personagens, que, no seriado, estavam na faixa dos 30 anos, no filme, aparecem com mais idade. Encontram-se na faixa dos 40 anos. Carrie (Sarah Jessica Parker) é a personagem hegemônica. $\mathrm{O}$ enredo se inscreve e se circunscreve no seu perfil de escritora, de sucesso, vivendo em Nova Iorque. Conta, ainda, com as suas amigas inseparáveis: Samantha Jones (Kim Catral), Charlotte York (Kristin Davis) e Miranda Hobbes (Cynthia Nixon).

Há uma metáfora no discurso do filme. Expressa que as mulheres que chegam a Nova Iorque buscam a Dior ou um amor. Parece resgatar a máxima de Shakeaspeare: "To be or not to be", como a pergunta, que elenca o sumário das questões filosóficas do universo feminino, dissociado entre o Amor e o Consumo.

Christian Dior nasceu em 21 de janeiro de 1905 e faleceu em 24 de outubro de 1957. Ele criou, em 1947, a Maison Dior de Alta Costura. Desenvolveu o conceito New Look, com os apelos da elegância, do lucro e da extravagância e exagero, usando grande quantidade de tecidos [(pt.wikipedia.org/wiki/Christian, $07 \mathrm{de}$ junho de 2009, às 9h)].

A Dior pode simbolizar a ponta de uma realidade. É a parte de um todo, chamado consumo. Ganha notoriedade, como se fosse um instinto natural da mulher. Ocorre uma fetichização. O cultural se desloca. Transforma-se em natural, em artigo de prioritária necessidade, indispensável nas lides do cotidiano.

Tal metamorfose retira da Moda o seu sentido efêmero, provisório. Concede-lhe outra perspectiva. Oferece-lhe um passaporte, para se tornar essencial. Deixa para trás a sua alegoria coadjuvante. Converte-se, através de uma moldura natural, em algo perene. Institui-se, como artigo de primeira e exclusiva necessidade.

A sua importância cresce. É equiparada ao Amor. Ambos se consolidam como manifestações do Desejo, ou seja, aquilo que falta, conforme Freud (1987). São os dois valores, que se dinamizam nas vitrines, com densidade e com intensidade. Assumem uma equivalência admirável, sem par.

O Amor e o Consumo são colados. Tornam-se frutos da mesma árvore. Configuram-se faces da mesma moeda. Estão em pé de igualdade. Simbiotizam-se, 
como se fossem tão iguais, como os mais iguais gêmeos univitelinos. À medida que se encontram colados, também estão descolados. São antagônicos.

Os desejos podem ser satisfeitos pelo Amor ou pelo Consumo. É uma coisa ou outra. Não existe equilíbrio. Parece não haver diálogos entre ambos. São, linearmente, excludentes no universo do protagonismo feminino. É uma coisa ou outra.

O Amor pode emblematizar o universo da subjetividade. Parece se comprometer com o Desejo de satisfação. Procura unir os diálogos entre sexo e afeto. É uma perspectiva do viver bem, alicerçada nas potencialidades de um ser pleno em suas possibilidades. É, em essência, um Valor de Uso.

O Consumo possui outros comprometimentos. Encontra-se imerso pelo valor de troca, no seu sentido econômico. Ancora as relações de individualismo, dominação e exploração. É um valor muito caro à produção e à reprodução do lucro no modo de produção capitalista. Representa a plenitude do funcionamento do universo do sistema.

A expansão do Consumo pode ser a vida do Capitalismo. Significa mais mercado, mais lucro. Tal maximização parece ser administrada por um pré-requisito. É a minimização da satisfação pessoal, para que o objeto do Desejo se projete, com ênfase, na tessitura dos apelos consumistas, e a eles sucumba.

As personagens talvez estejam envoltas em simbolizações. A advogada Miranda a relações públicas Samantha representam os valores do sistema capitalista. Articulam e são articuladas por
Discursos Encráticos - a produção de sentido, de acordo com os interesses da hegemonia vigente, conforme Barthes (1988).

Charlotte parece estar na outra margem do rio. É casada. Tem um filho adotado e, depois, dá à luz uma menina. Apresenta um mundo subjetivo, com mais equilíbrio. Cultiva uma convivência mais pacífica com o marido e com as relações domésticas. Talvez, por ter menos conflitos, se torne a mais discreta e anônima na passarela do enredo.

No protagonismo feminino, proposto pelo enredo, existe uma ênfase. É Carrie, escritora bem sucedida, que pode estar interpelada na busca do Amor e do Consumo. Move-se e é movida pelo objetivo do casamento, como consolidação de um relacionamento estável. Parece ser o mais sublime encanto de suas obsessões.

As quatro mulheres não são simples e descompromissadas integrantes da classe média norte-americana, em trânsito pela faixa etária dos 40 anos. Significam muito mais do que isso. São Personagens Conceituais, como concebem Deleuze e Guattari (1992), porquanto simbolizam ideias e configuram conceitos da vida e sobre o viver.

Miranda não consegue se desligar do mundo do sistema. Está sempre atropelada pela pressa. Em uma cena, pede ao marido para acabar logo com a relação sexual. O seu tempo, tal qual a máxima, talvez tenha se convertido na medida e no peso apenas do dinheiro. É um protótipo de personalidade pertinente às reivindicações do capitalismo.

Samantha possui um relacionamento com um ator de 
Hollywood. A imagem é o significante, que parece codificar o sentido de sua trajetória existencial. Dispõe de um homem bonito e famoso, mas, ao mesmo tempo, sente e consente com uma insatisfação, que a atividade sexual consegue deter e aplacar.

Carrie encontra Mr. Big (Chris Noth), um homem de finanças. Parecem compor o par perfeito. Os dois buscam o apartamento para morar. Tudo começa a dar certo no mundo subjetivo de ambos. A priori, foram feitos um para o outro. São tomados pelo sentido de que desta vez não tem erro. Tudo vai dar certo.

A felicidade da escritora é visitada e contaminada pelo grupo de amigas, sobretudo, por Miranda e Samantha. Os questionamentos da lógica do sistema capitalista não tardam. "Você vai morar com ele sem casar. O apartamento vai ficar somente no nome dele". É semeada a dúvida, através da ameaça da insegurança.

Miranda e Samantha são mulheres cercadas e envolvidas por frustrações. Estão insatisfeitas em seus relacionamentos. Projetam os seus conflitos no mundo e, particularmente, em Carrie, que os assume. Ela começa a cobrar de Big a necessidade de casamento, como uma consolidação oficial e legal do relacionamento.

Depois de Big aceitar a ideia do casamento, outra cobrança ingressa na pauta de Carrie. Ela deseja transformá-lo em um grande evento. A lista de convidados é maximizada. A noiva vira capa de Revista Vogue. Tudo se transforma. O casamento se converte em um produto massificado, com rótulo e cotação de mercado.
O Valor de Troca se apropria do casamento. Não é mais uma solenidade somente para os noivos, padrinhos e familiares. Converte-se em um evento, que transcende a territorialidade dos conhecidos. Abrange os sentidos dos desconhecidos. Assume uma configuração de mercadoria simbólica, que se sujeita às Leis de Oferta e Procura.

Lukács (1990) observou a importância do conceito de Reificação. Ele evidenciou que, no capitalismo, tudo se torna um produto a ser comercializado. Os ideais, as relações de afeto e os eventos sociais e da natureza acabam sendo apropriados. Ganham um rótulo e um preço. São agenciados como fontes econômicas, que possibilitam a reprodução do lucro capitalista.

O casamento de Carrie e Big vai, gradativamente, se esvaziando do seu Valor de Uso. Não é algo mais deles. Não possuem mais os vínculos de pertencimento. Foi cooptado, como mercadoria, por uma indústria e um comércio, que envolvem diferentes profissionais. Não é mais uma questão privada. Tornou-se uma questão pública, para satisfazer a sede e a gula dos interesses mercadológicos.

$\mathrm{O}$ contexto vai minando as certezas de Big. Ele possui um curriculum de casamentos fracassados. Agora, vê uma relação afetiva se transformar em uma obrigação solene de casamento, que não deve ser um comum e anônimo. Está vocacionado para ser o evento que contemple e preencha os apelos de frivolidade de um mundo, sem a régua e o compasso de valores reais e essenciais. 
O que deveria ser um evento de prazer, troca o sabor. Converte-se em algo desprazeroso. Adquire as cores e os tons de negatividade. Invoca e convoca os vídeos teipe do passado. Os fracassos, reprimidos no Inconsciente, ameaçam se materializar no presente sob o signo da Repetição. A insegurança cresce.

O conflito entre o que deveria ser e o que é assume contornos incontornáveis. O que poderia ser o bem se travestiu de mal. Os opostos, em seus antagonismos, estão presentes nos realismos objetivo e subjetivo. As imagens se desenham com os traços de filme de terror. São as Antíteses afirmando, imaginariamente, os conflitos inconscientes que transbordam para a Consciência.

A gota de água que faltava para completar a enchente não tardou. Miranda, que se separou do seu marido devido a traição, oportunizou o líquido fatal a Big. Observou-lhe que o casamento não fazia sentido. Estereotipou-lhe com a carga negativa do fracasso. Fez eco aos coros recalcados pelo Inconsciente. Colocou o noivo na contramão do caminho da igreja.

Ele acaba sendo vítima de seus próprios conflitos. Não vai à igreja. Quando tenta ir. É tarde. A noiva o rejeita. O casamento, que estava programado para ser um evento diferenciado, não ocorre. Tudo parece chegar ao fim sem uma causa aparente mas sustentado por um conjunto de causas.

O filme apresenta uma virtude básica. Conjuga em seus discursos uma agilidade. É leve nas construções das cenas comandadas pelo predomínio da ação. $\mathrm{O}$ movimento parece ser preciso através das qualificações estilís- ticas da clareza e da concisão. Há uma fluência que parece imitar o dinamismo da vida.

Os 148 minutos são breves. As cenas se evidenciam, analogamente, como se fossem vagões de um mesmo trem. São diferentes, porém conjugadas. Uma subsidia a outra. Há a evidência de que a sequência se desenvolve com fisionomia e feições da dinamicidade do cotidiano. Impera um nível de espontaneidade que mimetiza, com verossimilhança, os passos da dialética da vida.

A estrutura do enredo é costurada por um conjunto de Antíteses. Configura, imaginariamente, os conflitos materializados em linguagem. Toda a amarração de conflitos encontra uma perspectiva. Tudo acaba bem. Reina a paz. Carrie casa com Big em uma cerimônia simples. Miranda se reconcilia com o marido. Miranda se desembaraça de um relacionamento pouco satisfatório. Charlotte ratifica a paz doméstica com a chegada de uma filha.

O final feliz é a catarse lógica. Pronuncia os signos de uma Comédia Romântica. A idealização prevalece. Impõe-se em relação à historicidade e o relativismo realista. O que importa é terminar com a paz absoluta, como se Nova Iorque fosse o paraíso terrestre do modo de produção capitalista, o supremo e perfeito oásis.

\section{Significantes pós-modernos}

As Antíteses, as Repetições e as Imagens são os significantes de uma estética. É o estilo Barroco que parece dar as cartas e jogar de mão. Codifica a configuração do enredo, mesmo com as suas 
interpelações românticas que esvaziam a historicidade e dão plenitude ao sentido ahistórico em seus contornos metafísicos.

As Imagens são imperativas, conforme Barthes (1993). Apresentam uma pluralidade de signos. Impõem a significação de uma só vez. São os planos de expressão, próprios do Inconsciente, onde o enxergar é sinônimo absoluto de uma suprema e indiscutível verdade, desembaraçada do questionamento e da contradição.

Freud (1987) observou que a Linguagem do Inconsciente é, predominantemente, imaginária. O sonho, por exemplo, é um filme. Apresenta cenas, tomadas e determinadas sequências. Ainda que tenha Condensações e Deslocamentos, existe a presença hegemônica de significantes visuais.

As Antíteses e Repetições, de acordo com Barthes (1971), são manifestações do Fait Divers de Coincidência. O Fait Divers (casos do dia) é a informação sensacionalista. Explora, através da dramaticidade e da tragicidade, as emoções dos receptores. Não é preciso pensar. Cabe somente experimentar, livre e submetidamente, a emoção.

Os conflitos dramáticos e trágicos, fechados em seus próprios fatos, conduzem a uma noção. É a Fatalidade, um Sujeito Absoluto, de caráter ahistórico, que determina e explica as realidades humanas. É análogo ao Deus-ex-Machina, como a intervenção divina constante nas tragédias gregas.

No filme, a Coincidência mobiliza os sentidos dramáticos. A Fatalidade parece se particularizar, imaginariamente, com Tiquê, a deusa grega responsável pelo maniqueísmo do azar e da sorte.
Assume a responsabilidade dos impasses humanos, projetando a explicação em um ente metafísico, para se desculpar de suas culpas.

A figura de Tiquê, em uma leitura psicanalítica, pode ganhar outra versão. É o Inconsciente, com toda a sua carga de frustrações reprimidas, que atua e determina os passos existenciais. Não possui contradições. Absolutiza e ritualiza o recalcado como realidade única a ser vivida. É um Sujeito Absoluto que, em seus silêncios e falas, não cessa de atuar.

Baudrillard (1990) evidencia que a Mídia possui uma lógica. Os seus diferentes espaços e gêneros são mobilizados pela presença do Fait Divers. É a invariância da presença do Sensacionalismo, como interpelação básica, para fisgar as audiências em diferentes horários e gêneros midiáticos.

Maffesoli vislumbra aspectos positivos no Fait Divers. Ele salienta a possibilidade de romper com o racionalismo, que marca e demarca o cotidiano. É revelador da realidade social. Põe em destaque a extensão e a importância da anomalia. "A monstruosidade, em seu sentido etimológico, é cotidiana - e somente as 'belas almas', ou os moralistas a denegam" (MAFFESOLI, 1988, p. 196).

A Pós-Modernidade é a conjunção do arcaico com o desenvolvimento tecnológico, sublinha Maffesoli (1990). Caracteriza-se pelo seu estilo Barroco. Evidencia-se, também, pela Cultura de estar-junto, pela hegemonia da Imagem, como significante, pela Esquizofrenização e pela hegemonia do Presente.

Em Sex and the City, a Cultura de estar-junto parece estar 
configurada no grupo, constituído por Carrie, Miranda, Samantha e Charlotte. Elas são quase inseparáveis. Cultivam, nas suas autonomias, as dependências e a obrigatoriedade de compartilhar tudo sobre o vivido. O Presenteísmo é a unidade temporal prioritária.

O grupo parece, analogamente, se configurar no grande Espe1ho. Mostra os reflexos que podem unificar. Esconde, ao mesmo tempo, o que não lhe interessa. $\mathrm{O}$ que se afina com a sua Ideologia - o seu discurso-referência, de acordo com Maffesoli (1988, p. 36) - do Narcisismo como um senhorio e servo dos significantes imagéticos do aqui e agora.

As quatro amigas se dizem autônomas, porém saboreiam, concomitantemente, uma dependência. Não vivem sem a convivência grupal. Podem se sentir tais quais adolescentes inseguras, como pessoas físicas. Necessitam da pessoa jurídica, o grupo, para unificar as suas identidades, para encontrar um estilo e para resgatar uma autolegitimação. É preciso proteger e de autoproteção de suas Imagens.

Todas convivem com a faixa etária dos 40 anos, mas, emocionalmente, parecem assumir um comportamento próprio do período da Adolescência. Coabitam, nelas, uma Antítese que simboliza a densidade e a intensidade de um conflito. São adultas na idade, mas adolescentes no comportamento e nas suas práticas emocionais.

Tal Antítese é ritualizada pelo grupo. Traz consigo as figuras da Repetição. Ambas configuram a noção de Coincidência, que conduz a uma conotação. É a Fatalidade, o Sujeito ahistórico, que as uniu e que permite as suas perenes reuniões no curso da existência compartilhando as suas experiências.

A Repetição é significativa no grupo. Parece uma forma de defesa em relação ao envelhecimento. Caracteriza-se por ser obsessiva. "Constitui, sem dúvida, uma maneira de dizer e de negar o tempo que passa - e é, neste sentido, que a repetição cíclica é um escudo eficaz", como evidencia Maffesoli (1988, p. 176)

A autonomia e a dependência grupais. Trazem, em seus bastidores de sentidos, outra simbolização. É a pulsão de dar uma marcha a ré no tempo. As certezas dos avanços dos anos parecem carecer de um conjunto de incertezas joviais. Existe um imperioso pré-requisito. É ingressar num túnel do tempo e regredir até uma apoteose de ser, simplesmente e intensamente adolescente.

Carrie, Miranda, Charlotte e Samantha são mulheres aparentemente bem resolvidas. Pertencem ao universo da classe média nova-iorquina. São profissionais. Ostentam os crachás de seus êxitos. Têm acessos às indústrias de cosméticos e da moda. Não querem parar no tempo. Não podem envelhecer. Precisam permanecer eternamente jovens.

Todas carregam um desejo inconsciente. Querem, reivindicam e se vocacionam para um mito. É o de Hebe, a eterna jovem no Olimpo da Mitologia grega. Só assim poderão resgatar os apelos permanentes de seus Inconscientes, em que a bela Imagem é simplesmente o tudo, para sustentar o orgulho e a arrogância narcísicas.

O tempo deve ficar fixo. Necessita de um Mandrake. Precisa ser colocado no formol ou na 
conserva. Carece de não ser dinâmico. Deve, a todo custo, ser detido, preso e algemado pelas ilusões, arrogâncias e os orgulhos de quem quer copidescar a realidade, conforme os seus interesses narcísicos, senhores e escravos das superfícies dos espelhos.

As protagonistas de Sex and the City não podem crescer. Não devem adquirir a maturidade. Isso possui um sentido desastroso e catastrófico, para os traços de suas respectivas Imagens. Isso é envelhecer. Socorro! Chamem a Dior, Chanell e a Avon. Telefonem para todos os cirurgiões plásticos. Viva o botox e todos os bisturis de Helena de Tróia!
Portanto, em Sex and the City, o protagonismo feminino na PósModernidade singulariza algumas práticas e traços específicos. É a Esquizofrenização - a fragmentação das partes e do todo. É preciso viver sem envelhecer, ficando uma Hebe para todo o sempre. Há necessidade de amar, mas a impossibilidade de unir o sexo ao afeto. O Amor e a Dior são indiferentes. Significam quase a mesma coisa. Ambos satisfazem e são insatisfatórios. Não atenuam os conflitos das almas aprisionadas à Histeria - a perene insatisfação de quem não alcança a plenitude -, projetada nas vitrines das ilusões sempre jovens do Consumo.

\section{Referências}

BARTHES, Roland. O Rumor da Língua. São Paulo: Brasiliense, 1988. . Mitologias. Rio de Janeiro: Bertrand Brasil, 1993.

. Ensaios Críticos. Lisboa: Edições 70, 1971.

BAUDRILlarD, Jean. A Sociedade de Consumo. Rio de Janeiro: Elfos, 1990.

DELEUZE, Gilles e GUATTARI, Félix. O que é Filosofia? Rio de Janeiro: Editora 34, 1992.

FREUD, Sigmund. A Interpretação dos Sonhos. Rio de Janeiro: Imago, 1987. v. 2

LUKÁCS, Georg. História e Consciência de Classe. São Paulo: Elfos, 1990.

MAFFESOLI, Michel. O Conhecimento Comum: Compêndio de Sociologia Compreensiva. São Paulo: Brasiliense, 1988. . No Fundo das Aparências. Petrópolis: Vozes, 1990.

WIKIPÉDIA. pt.wikipedia.org/wiki/Christian>. Acesso em: 07 de junho de 2009.

Data do Recebimento: 10/09/2009

Data do Aceite: 29/10/2009 